\title{
Training of engineering personnel in the Sevastopol State University on the basis of the project "Synergy"
}

\author{
${ }^{1}$ Sevastopol State University, kramarv@mail.ru \\ ${ }^{2}$ Sevastopol State University, kabanov@ sevsu.ru \\ ${ }^{3}$ Sevastopol State University, alchkov@ sevsu.ru \\ ${ }^{4}$ Sevastopol State University, VRDusko@sevsu.ru
}

V.A. $\operatorname{Kramar}^{1 * *}$, A.A. Kabanov², V.V. Alchakov ${ }^{3}$ and V.R. Dushko ${ }^{4}$

\section{Abstract}

In the article, the problems of modern engineering training are discussed. The practice of Sevastopol State University in this field is represented. The participation of the university in the international project "Synergy" is described.

\begin{abstract}
Keywords: Synergy Network, international educational project. training engineers, educational process, teaching and methodological support

Received on 04 December 2017, accepted on 29 January 2018, published on 10 July 2018

Copyright (C) 2018 V.A. Kramar et al., licensed to EAI. This is an open access article distributed under the terms of the Creative Commons Attribution licence (http://creativecommons.org/licenses/by/3.0/), which permits unlimited use, distribution and reproduction in any medium so long as the original work is properly cited.
\end{abstract}

doi: 10.4108/eai.10-7-2018.155047

\section{Introduction}

A specific feature of modern universities that have technical profile makes it necessary to allocate large amounts of money for the renovation of the material base, primarily those that produce departments. This process is difficult to implement in a short time, associated with the release of engineering personnel (4-6 years).

The training of specialists in modern conditions is characterized by a high degree of theorized knowledge and almost complete lack of access by students to modern knowledge in the field of design. Modern economy requires the influx of a large number of young professionals with modern knowledge in science. It is necessary not to allow the preparation of students to lag behind the intensively developing industrial production and, accordingly, the changing curricula.

The distribution of modern, often unique equipment, both between the graduating departments and between the universities, does not allow to effectively solve the problems of the organization of the educational process in order to use it in the preparation of students of related specialties, in time and qualitatively developing methodological support, creating integrated training systems and complexes that are the link between students of different engineering directions, and also to carry out with the minimum time and financial expenses their updating, service and repair.

A significant role in the modern training of an engineer is devoted to lean manufacturing, including studying them with modern material-saving and energy-saving technologies, which requires the creation of a specific material and methodological base for the machine-building, instrument making and mechatronic profile, supplemented with equipment and techniques for conducting energy audits.

The presence of a modern multipurpose material and technical base allows us to develop the latest engineering high-tech areas such as mechatronics, robotics, technology, shipbuilding and a number of others, to attract students and beginners to them, to create advanced competencies for students, allowing them to easily adapt to modern production after graduation.

${ }^{*}$ Corresponding author. Email: kramarv@mail.ru 


\section{Realization of the international educational project "Synergy" in Sevastopol State University}

At present, software and technological equipment are being intensively developed and implemented in the educational process. It is often difficult for most universities of training technicians to adhere to the pace of equipment renewal, given the speed of modern technological progress. Universities do not have enough specialists, money and time. Therefore, the solution of this problem for universities becomes more and more complicated. One of the ways to solve the problem is to merge the scientific, technical and educational resources of universities. With such a merger, each university can develop topics for which it has the experience and high potential, corresponding, often unique technological equipment, and at the same time can use the results of developments of other universities.

The most difficult part in such a merger is the unification of educational laboratories equipped with modern high-tech equipment. When solving this problem, students of different universities should have access to remote equipment installed in various educational institutions, via the Internet without direct access. At the same time, students and their teachers should change the usual idea of working with equipment. In addition to taking into account the psychological aspects, special software and methodological support should be developed to manage remote access to equipment and obtain information about the results of management from it.

Problems of remote interaction with this or that kind of equipment have been solved in a number of universities. In the US and Mexico, this task was solved within the Digital Factory project of a university network that united three universities [1]. In the European Community, 11 partner universities have developed the Marvel project, which has a large scale [2].

However, until recently, there was no interuniversity networking uniting high-tech laboratory equipment, and there was no distributed laboratory system that could provide regular training for university students. For the first time such a task was carried out within the framework of the "Synergy" project, which united a single goal - the training of highly qualified specialists of technical orientation using a network of high-tech laboratories.

At the Sevastopol State University, in close cooperation with the industrial company FESTO and universities: Moscow Power Engineering Institute, Baltic State Technical University, Omsk State Technical University, St. Petersburg State Technical University, Karagand State University, the networks of training laboratories were created, tested and put into operation for the preparation of students in a number of high-tech areas of modern industry [3].

The project "Synergy" is designed to teach students how to develop systems for automatic control and monitoring of technological processes with the help of specialized software on a virtual and physical model of such equipment.

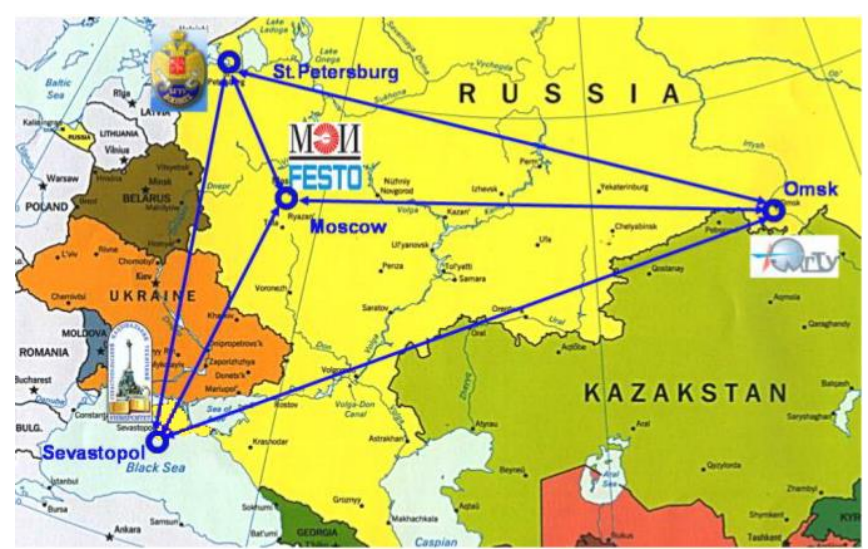

Figure 1. A map of interaction between "Synergy" project partners

The authors of the Marvel project mentioned above clearly explained why virtual and physical models are needed [4] and why real equipment can not be replaced by its virtual models [5]. Also in this project was proved the possibility of remote access to real equipment and some problems associated with such access [6].

The "Synergy" project laboratories in the beginning of their existence were developed on the basis of the simulation of the modular production systems (MPS) "FESTO" (testing, moving, assembly). These systems include real drives, sensors, controllers and physical models of industrial equipment. For each system, a simulator was implemented. These simulators can work with both virtual and real controllers.

In order to show students how the design process should be organized, and to protect real equipment from erroneous actions, all classes begin with exercises on the simulators and with the use of appropriate methodological recommendations and teaching aids.

As mentioned above, eEach university - participant of the project "Synergy" has educational high-tech laboratories and Internet laboratories. Workstations of students in the class are personal computers, united by a local network with Internet access. In the software libraries of computers, virtual models of all modular production systems are installed.

Students, using virtual models, prepare control programs for the controllers of modular production systems and send them through the local network to the main server.

The organizational structure of the system is shown in Fig. 2.

The main server has a folder for each student. Access to this folder the student receives after he submits his password. The folder consists of two parts: "Lesson" and "Output". The student program is loaded into the "Lesson" part.

The folder structure on the main server is shown in Fig. 3. 


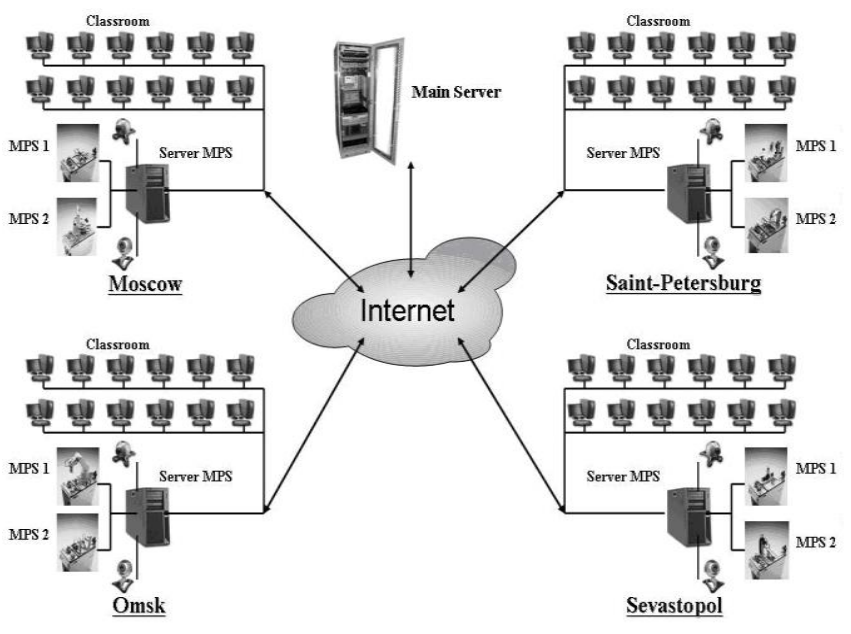

Figure 2. Organizational structure of the system of access to equipment

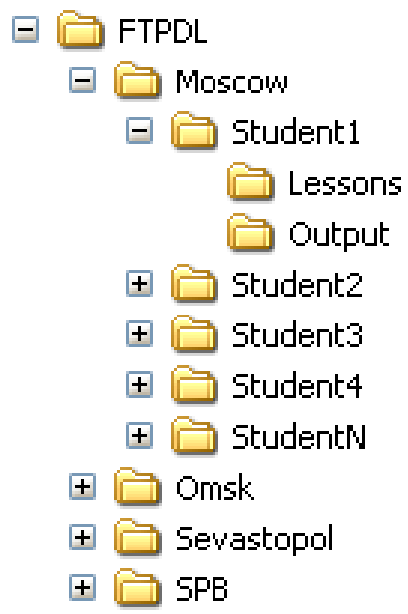

Figure 3. Structure of the main project folder

Modular production systems are installed in the Internet laboratory. Each laboratory has a local server. This server provides communication between the stations and the main server.

Appearance of the robotic modular production system designed for solving tasks of transportation, orientation and loading / unloading of production facilities is shown in Fig. 4.

The main server contains student programs in the queue and constantly interacts with local servers. When a ready signal from the local server appears on the master server, it sends the first program from the queue, using the appropriate local server to the assigned modular production system controller. Simultaneously, the main server sends a command to turn on the television cameras aimed at the modular production system to fix its operation.

The control program starts working immediately after it is loaded into the controller. A modular production system runs a predetermined time, or until one of the controlled parameters begins to exceed the allowable level.

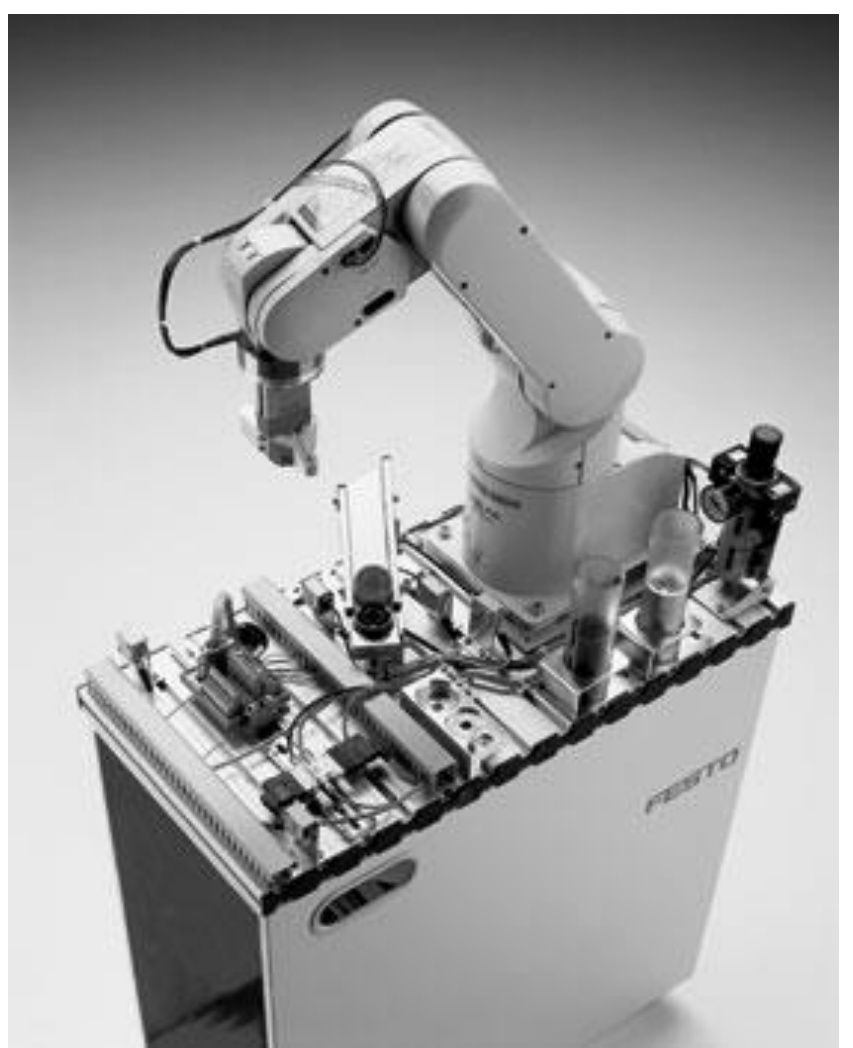

Figure 4. Appearance of the modular production system

All signals of the sensors of the modular production system functioning, television signals are fixed in the student's folder, in the "Output" part. A student can obtain information and analyze it right after the modular production system has been stopped or later, when it is convenient for students. The contents of its folder will be maintained throughout the learning period.

The project participants have the opportunity to develop software for remote access to the modular production system in on-line mode. This mode of work is necessary for the independent work of the student. In this case, the experiments can follow one another without interruption.

The student has the opportunity to start and stop the program at his own discretion. In the "on-line" mode, the main server forms animated images of the modular production system for students. The results of the work can be displayed both on students' computers and on a monitor in a specialized lecture room equipped with a video / audio system during lecture classes.

Within the framework of the project, a broadband connection to the Internet is established in the St. Petersburg State University and universities, and this connection provides an opportunity for teachers to lecture for all universities simultaneously with the help of trained audio and video facilities. It is also possible to hold consultations for students on these channels.

Further development of this system in the project "Synergy" can give an opportunity to receive a full-fledged technical education not only for students, but also for 
everyone who wishes within the organization of additional education.

The created structure can be expanded and supplemented with new techniques, techniques and new participants.

\section{The structure of the SevGU for the implementation of the project "Synergy"}

Since its inception, the Sevastopol State University (SevGU) has become the main center for the training of engineering personnel for all spheres of the economy.

The university is preparing for various engineering fields, including automation, shipbuilding, technology and automation, and energy. The basis of the university development strategy is that qualitative training of a modern engineer is impossible without scientific and industrial interaction with large corporations and international organizations.

SevGU has been successfully cooperating with Festo (Germany) for a long time, with the participation of which a center for the training of modern engineers has been established within the university.

At the present time, a collective has been formed in the University of SevGU, capable of carrying out research and development in various areas of modern engineering. Given the market situation, the University maintains a number of projects that may be of interest to various enterprises, including equipment suppliers and technical solutions.

In SevGU there are 8 training laboratories, in which the equipment and methodological documentation, available for students of almost all technical specialties, are concentrated for the intended purpose.

The preparation of students of technical specialties is realized in laboratories, the technical equipment of which allows to carry out in addition to theoretical practical training in disciplines related to the automation of technological processes, management of technical systems, industrial mechatronics and robotics, sensorics of automated technological systems [7].

This direction is provided by the following laboratories:

- Laboratory of control systems;

- Laboratory of industrial mechatronic systems;

- Laboratory of sensorics of automated technological systems;

- Laboratory of elements and systems of automated hydraulic drive;

- Laboratory of elements and systems of automated pneumatic drive;

- Laboratory of automated electric drive;

- Laboratory of mobile systems management.

All the performed laboratory works are directed not only to the study of the structures and the principle of action, which is part of the laboratory equipment of technological automated equipment, but also has a research component that allows future engineers to develop practical skills in organizing and conducting research of their various static and dynamic characteristics.

\section{Laboratory of control systems}

The laboratory includes the following training and research equipment:

- Pneumatic system of two-coordinate positioning on the basis of rodless pneumatic cylinders and SPC200 controller of firm FESTO;

- Hydraulic station for the study of continuous processes, which allows monitoring temperature, pressure, flow rate and liquid level;

- Pneumatic gate valves of ship pipelines, controlled by a modular system including FEC controller FESTO;

- Belt conveyor controlled by the LOGO controller;

- Manipulation mechanism based on pneumatic fuseliers, controlled by FESTO controller FESTO;

Laboratory carries out laboratory and term papers on the following disciplines: automatic control theory; automation systems; computer simulation of processes and systems; optimal and adaptive systems; digital control systems.

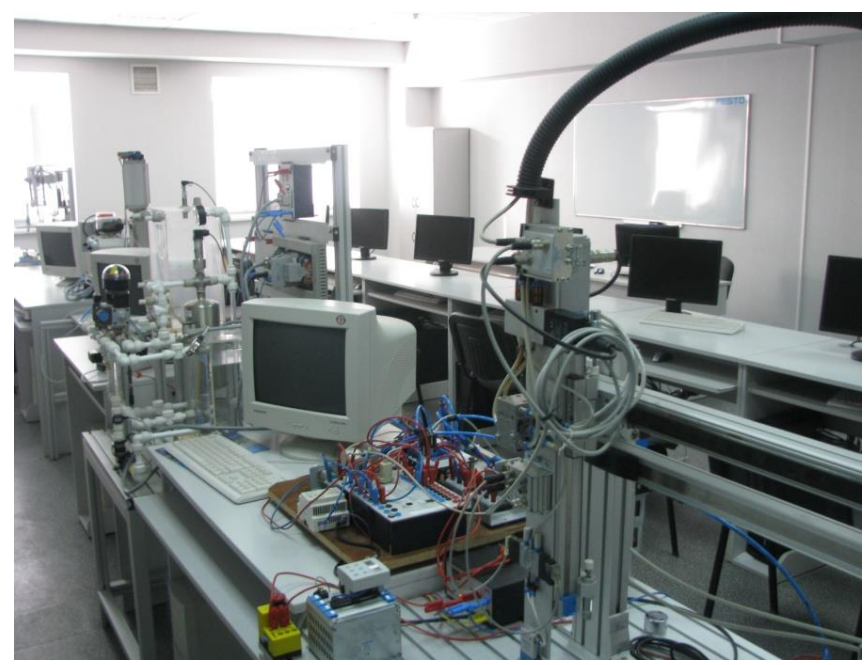

Figure 5. Control Systems Laboratory

The educational process in the center is built according to two schemes. The first scheme based on classical approach. Before the beginning of the work, the student studies the theoretical material, studies the methodological instructions describing the work and installation and carries out the task of studying the properties of equipment and operating principles. The second scheme implements a project approach, in which the student designs a given device using the components of laboratory stands. As a task, he gets the requirements for the created installation (functional properties and parameters).

And since laboratory stands didactically model real production systems, the second approach is also implemented when students complete graduate and graduate work in which 
students design systems and complexes that simulate real production processes, for example, the assembly line [8, 9].

Before collecting the installation, both in the first approach and in the second scheme are modelled in specialized software and after the teacher checks the correctness of the system it is realized on the basis of the stands [10].

To maintain the acquired knowledge during the entire period of training, tests (sometimes in the form of tests) are conducted to analyse the level of residual knowledge of students on the topic.

As can be seen from the proposed educational approaches, the main educational vector is the research vector. The student either studies the properties of various systems, sensors or the principles of their work according to the algorithms given to teachers. Or, in the implementation of the second approach, the student examines the elements of the stands and the principles of their work in the framework of the project task.

The existing equipment and the "Synergy" approach developed within the framework of the project also allows online use of remote equipment available from partner universities and perform research according to the accepted protocols of exchange and interaction $[11,12]$.

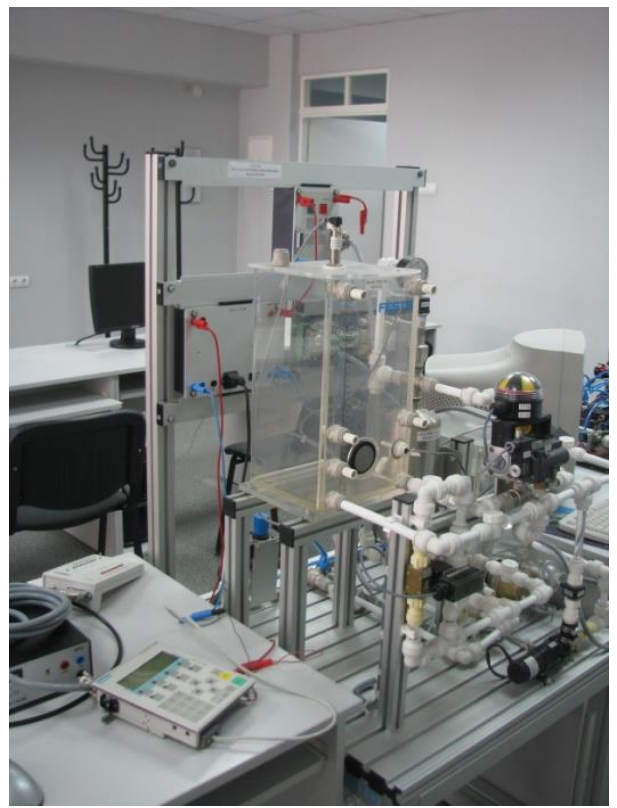

Figure 6. Hydraulic Station for the study of continuous processes

\section{Laboratory of industrial mechatronic systems}

The laboratory conducts laboratory and practical classes in the disciplines: the design of automated technological systems; system analysis of complex control systems; software control of equipment.

The laboratory includes the following equipment:

- Five modular-production systems for various technological processes;

- Lathe with programmed control;
- Industrial robot "Mitsubisi" with electric drives;

- Buffer storage system for loading / unloading lathe;

- Control station for liquid spillage of technical and food.

The laboratory conducts laboratory and practical classes in the disciplines: the design of automated technological systems; system analysis of complex control systems; software control of equipment.

As examples of laboratory works performed by university students, you can specify: "Study of the loading module of the automatic line"; "Study of the structure and study of the main characteristics of the automatic line control module"; "Study of the structure and investigation of the main characteristics of the technological module of the automatic line"; "Study of the structure and study of the main characteristics of the transport module of the automatic line"; "Study of the structure and investigation of the main characteristics of the automatic line sorting module".

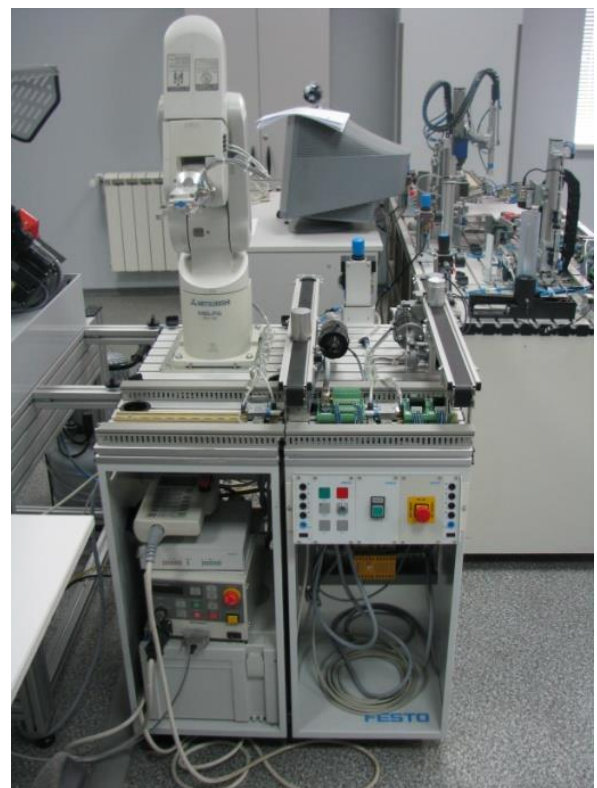

Figure 7. Industrial robot "Mitsubisi" with electric drives

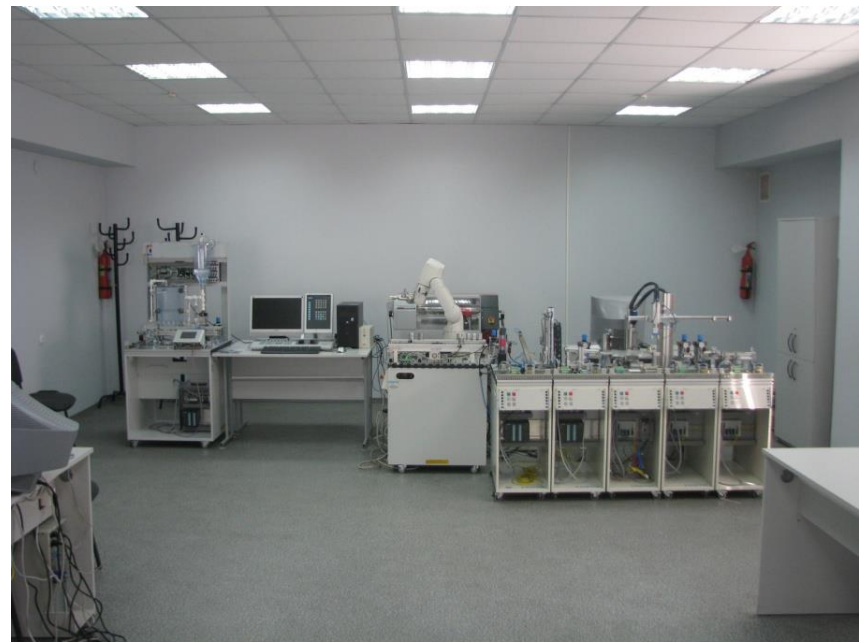

Figure 8. Laboratory of industrial mechatronic systems 


\section{Laboratory of sensorics of automated technological systems}

The laboratory is designed to study and study by students the characteristics of measuring transducers and sensors based on them. The laboratory includes:

- A set of sensors for measuring the pressure forces of the executive bodies of process equipment, working media;

- A set of sensors for monitoring the accuracy of positioning of working elements and production objects, movements and processing quality;

- A set of discrete sensors of contact and non-contact types;

- The laboratory has 27 seats and 14 personal computers connected to a local network connected to the "Uran" network.

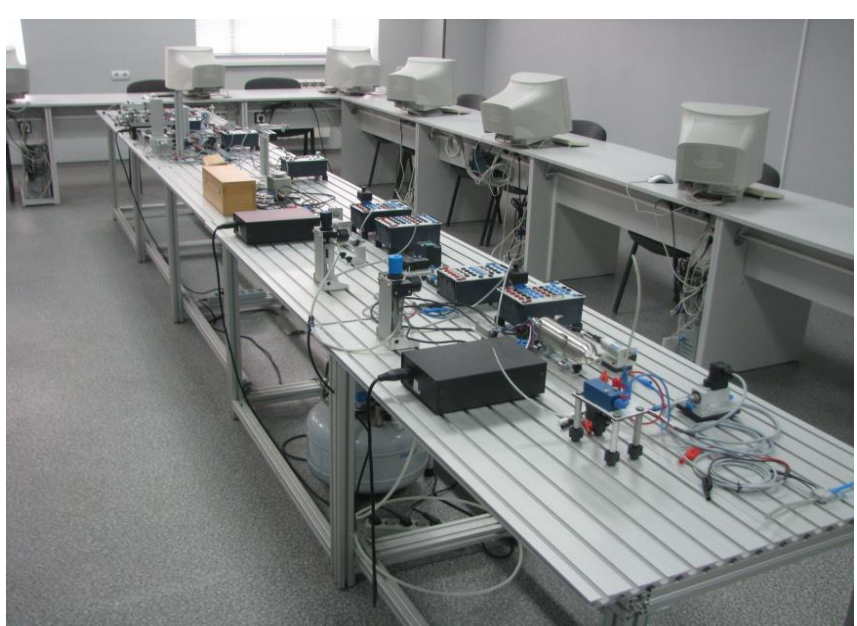

Figure 9. Laboratory of sensorics of automated technological systems

The number of laboratory works performed by students of the University includes: "Investigation of tensometric force transducers"; "Investigation of converters for pressure monitoring"; "Investigation of a non-contact inductive converter"; "Potentiometric and ultrasonic transducers"; "Investigation of the optical converter"; "Investigation of a discrete capacitive sensor".

\section{Laboratory of elements and systems of automated hydraulic drive}

The laboratory is equipped with two two-way universal laboratory stands of the firm FESTO, each of which allows simultaneous work to two teams (usually consisting of two students). The laboratory performs a complex of laboratory works on hydroautomatics and hydraulic drive, local systems of hydroautomatics, research of dynamic processes in the hydraulic drive. All laboratory schemes are first practiced on virtual models - on a PC using the "FluidSim" program, and only then on laboratory equipment.

The laboratory kit of one stand allows to assemble up to 20 different laboratory installations.

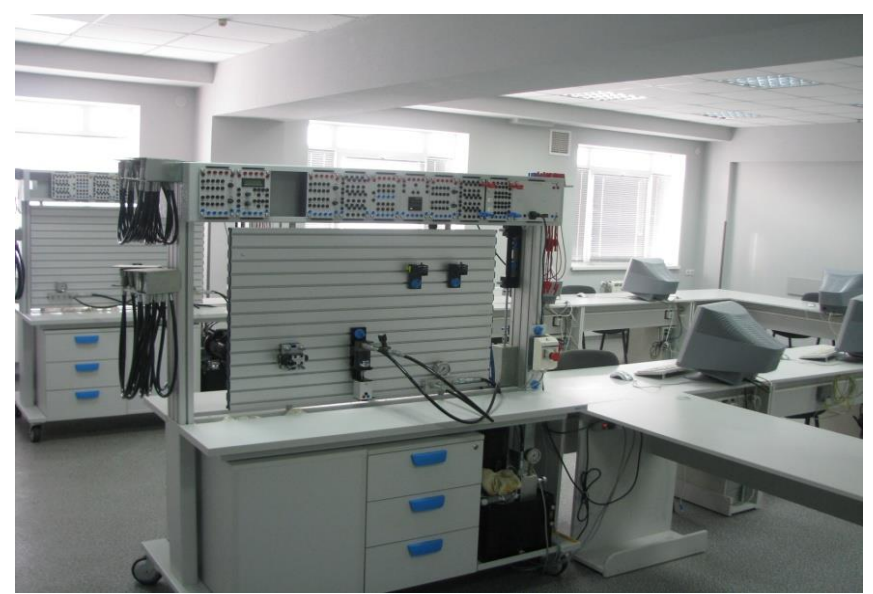

Figure 10. Two-way universal laboratory hydraulic stand of the firm FESTO

\section{Laboratory of elements and systems of automated} pneumatic drive

The equipment of the laboratory is represented by five double-sided stands, allowing simultaneously to twenty students to carry out a complex of works on pneumoautomatic and pneumatic drive, electro pneumatic automation, pneumatic logic, proportional pneumatic automation and pneumatic drive and also on dynamic processes in the pneumatic drive.

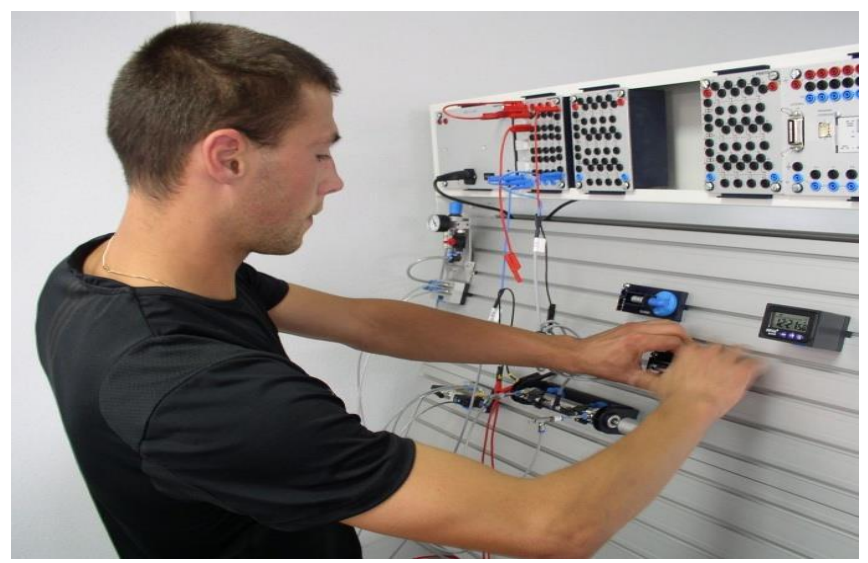

Figure 11. The automated pneumatic drive stand

A laboratory kit of a single stand allows the collection of up to 20 types of laboratory facilities for laboratory work such as:

- Investigation of pneumatic actuators with one pneumatic cylinder of one- and two-way action;

- Study of the characteristics of a double-acting pneumatic cylinder with variable load on its rod;

- Research of operational characteristics of pneumatic distributors with pneumatic control;

- Implementation of logical operations on high-pressure elements; 
- Analysis and synthesis of pneumatic control schemes for pneumatic engines based on the logical elements "AND", "OR";

Investigation of electro pneumatic circuits of discrete control of pneumatic actuator with one executive motor.

\section{Laboratory of automated electric drive}

The complete set of laboratory units includes servo and stepper motors, linear electric drives, FESTO controllers and SIEMENS controllers, which allow controlling actuators by means of programs developed and debugged on computers.

As examples of laboratory works performed by students of the University, you can indicate: "Investigation of the operation of the FEC FC620 programmable logic controller with an optical sensor"; "Investigation of the FEC FC620 programmable logic controller with a DC-DC electric motor based on the MTR-DCI type engine"; "Investigation of an electromechanical system with an electric servomotor for alternating current and a control controller"; "Modeling the dynamic process of an electromechanical automatic control system"; "Simulation of starting an asynchronous electric motor on a computer"; "Simulation of starting the DC motor on a computer"; "Study of a non-linear system for automatic control of a DC motor".

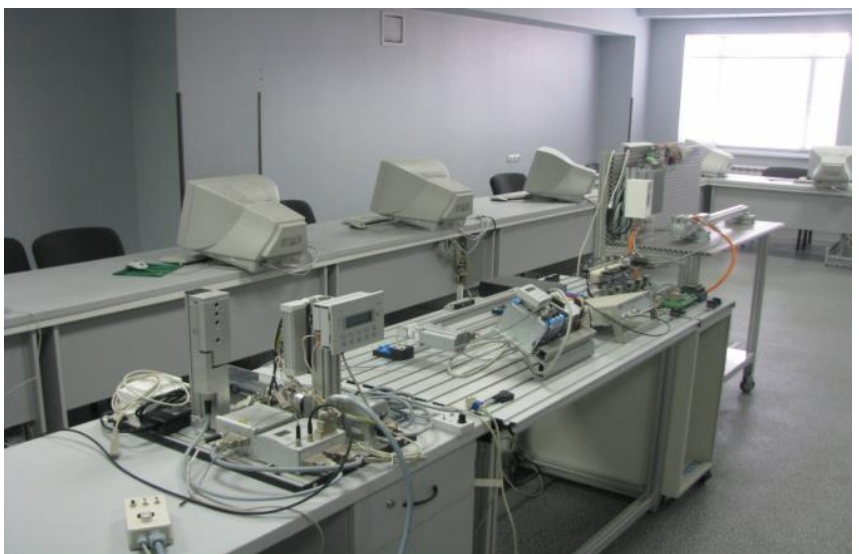

Figure 10. Laboratory of automated electric drive

\section{Laboratory of mobile systems management}

In the laboratory of motion control of industrial robots, fixed are the laboratory complexes for the study of the laws governing the mobile robot with roller-bearing wheels Robotino. The laboratory conducts practical work within the disciplines: theory of automatic control, optimal and adaptive systems, digital control systems. Students practice the application of various control laws (optimal, terminal, adaptive) to complex systems of automatic control using the example of a mobile robot. The researches carried out in the laboratory are used by students in the preparation of graduate works of bachelors, diploma projects of specialists and graduate works of masters. As examples of diploma projects and graduate works, you can specify: "Robotino mobile robot control algorithms for engine angular velocities and equations of calculation"; "System of optimal stabilization of movement of the mobile robot Robotino"; "Identification of the characteristics of the mobile robot Robotino"; "Terminal control of a mobile robot".

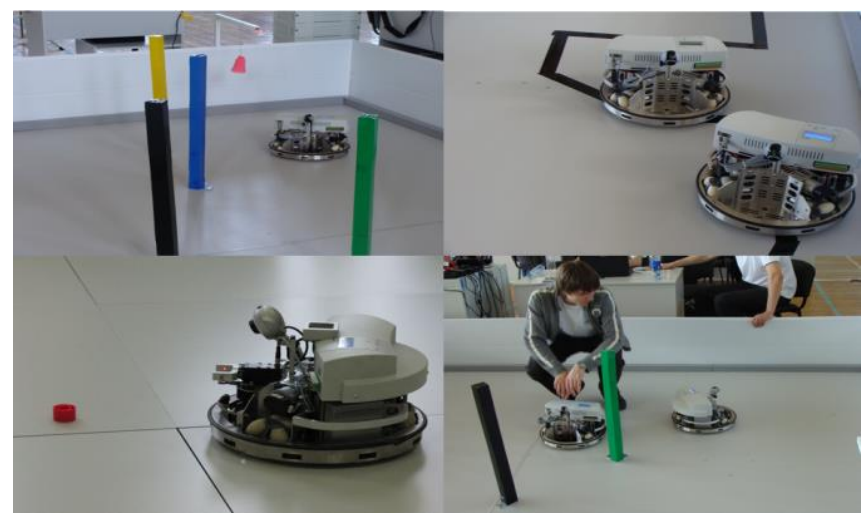

Figure 11. Conducting laboratory works in the laboratory of mobile systems control

\section{Conclusion}

In the conditions of modern globalization, open borders, availability of intellectual resources of the Internet, the training of engineers can and should be aimed at educating specialists on the basis of world knowledge, with the ability to solve complex problems and with the experience of international communication.

Currently, on the basis of the University, it is already possible to conduct distance learning for FESTO clients, both in the theoretical and practical directions.

\section{References}

[1] PAKKala, J.E.; LOPEZ, F.J. (2006). Work in progress: Implementing a digital factory university network, 14244-0257-3, 36th ASEE/IEEE Frontiers in education conference, T1A1-2, 2006, San Diego

[2] MulLER, D. (2005). The MARVEL project, 3-88555-769$\mathrm{x}$, Marvel, 2005, Bremen, 7-16.

[3] Bagimov, I., Klevakin, V., Kramar, V., Mikhailov, M., Mogilnikov, P., Roslyakov, P., Shalai, V., Stazhrov, S. (2007). International Educational Project "SYNERGY", Annals of DAAAM for 2007 \& Proceedings of the 18th International DAAAM Symposium, Katalinic, B. (Ed.), 473-474.

[4] Bruns, F.W.; ERbe, H.-H.; FAust, M. (2005), Engineering future laboratories, 88555-769-x, Marvel, 2005, Bremen, 83-91.

[5] Clark, G.; WeIR, G. (2005). Remote workshop in mechatronics: course trial and evaluation at West Lothian College, 3-88555-769-x, Marvel, 2005, Bremen, 63-72.

[6] KARlsSON, P., Hrissagis, K. (2005), Remote programming and configuration of a robotic system: a workplace oriented case study, 88555-769-x, Marvel, 2005, Bremen, 73-82.

[7] Pashkov, Y., Kramar, V., Bagimov, I., Alchakov, V. (2010) The international project "Synergy". In Proceeding of the 9th International Conference on Information 
Technology Based Higher Education and Training, 29th April - 1st May 2010, Cappadocia, Turkey.

[8] Kramar, A., Alchakov V., Bagimov I. (2007) On the creation of distributed laboratories of automation systems and means within the framework of the project "Synergy". In Materials of the 7th International Scientific and Methodological Conference "Distance Learning Educational Environment of the 21st Century", Minsk, BGUIR, 78-79.

[9] Svetlichny, P., Alchakov V., Kramar V. (2008). The conception of the virtual learning centre for the tasks of remote education. In Proceeding of the 15th international conference on automatic control, September 2008, ("IzdatInform" ONMA, Odessa), 514-516.

[10] Bagimov, I., Konobritskiy, D., Kramar, V. (2008) Software product "DISTEDU" for distance education lessons. In Materials of the 2nd European DAAAM International Young Researchers' and Scientists' Conference 22-25th October 2008, Slovak University of Technology, Trnava, Slovakia.

[11] Kramar, A., Alchakov V. (2007) About the approach to the development of the system of remote access to educational resources SevNTU. In Materials of the scientific-methodical conference "New methods of training engineering personnel", Sevastopol, SevNTU, 34.

[12] Kramar, A., Alchakov V. (2007) The practice of introducing elements of the distance education system SevNTU. In Materials of the 7th International Scientific and Methodological Conference "Distance Learning Educational Environment of the 21st Century", Minsk, BGUIR, 24-26. 